\title{
MacImage: a user-friendly image-analysis system for the accurate mensuration of marine organisms
}

\author{
Kenneth W. Estep*, Ferren MacIntyre, Einar Hjörleifsson \& John McN. Sieburth \\ Graduate School of Oceanography, University of Rhode Island, Bay Campus, Narragansett, Rhode Island 02882-1197, USA
}

\begin{abstract}
Changes in abundance, dimensions, and biovolume of marine microorganisms are important parameters used in the estimation of a wide range of biological processes, including cell activity, growth rate, predation, and nutrient cycling. Routine measurement of these parameters has been hampered by the tedium of counting and measuring large numbers of microorganisms, the subjectivity of visual measurement using the eyepiece micrometer, cell shrinkage during preparation for electron microscopy, and the small size of marine bacteria and some protists. Image-analysed microscopy overcomes these problems, but extant equipment and programs are cumbersome. MacImage, an image-analysis system that interfaces an Artek $810 \mathrm{~V}$ image-analysis computer and a Macintosh computer, has been developed using the language Forth to improve operator-machine control and versatility. By using a combination of a more sensitive camera tube, additional magnification lenses, and a software system for the Macintosh computer specifically tailored for the measurement of marine microorganisms, we are now able to accurately and rapidly determine the abundance, size, shape, volume, and surface area of microorganisms ranging from marine bacteria to fish larvae. Data collected by this system can be transferred directly to other Macintosh spreadsheet and graphics programs. To illustrate the versatility of MacImage, we present data on size, biovolume, biosurface area, and abundance of a natural sample of picoplankton from Narragansett Bay, Rhode Island; size and biovolume data on a cultured clone of Synechococcus; and size, shape and area on the larvae of the winter flounder Pseudopleuronectes amencanus.
\end{abstract}

\section{INTRODUCTION}

The determination of the abundance and sizes of marine microorganisms is of interest to a wide range of marine scientists. Marine microbiologists expend much effort in determining numbers and biomass of marine bacteria and nanoplankton (Bratbak 1985, Laanbroek \& Verplanke 1986). Zooplankton ecologists are concerned with size structure, species identification and total counts of natural samples (Jeffries et al. 1984, Rolke \& Lenz 1984). Fish population dynamicists are concerned with fish egg and larval sizes in relation to physiological conditions, growth rates, survivorship, and ultimately recruitment (Blaxter \& Hempel 1963, Bulow 1970, Lasker 1981). Despite the importance of these parameters, there is no reliable method for their rapid estimation. In the case of larger organisms in the microplankton (20 to $200 \mu \mathrm{m})$ and mesoplankton (0.2 to $2 \mathrm{~mm}$ ), accurate measurements can be obtained, but at

- Present address: Institute of Marine Research, Directorate of Fisheries, P. O. Box 2906, N-5011 Bergen-Nordnes, Norway the expense of many hours of tedium with an eyepiece micrometer. In the case of smaller organisms in the picoplankton and nanoplankton, accurate estimation of size, biovolume and biomass is hampered by their small size, and their shrinkage during preparation for electron microscopy (Zimmermann 1977. Fuhrman 1981, Bratbak 1985).

Automated image analysis has been used since the $1950^{\circ}$ s for counting and sizing a wide variety of objects, including coal particles in air (Watson 1952), leukocytes in blood (Ingram \& Preston 1970) and bacterial cells in milk (Pettipher \& Rodrigues 1982). Image analysis has been used in the marine environment for estimating the size of algae (Furuya 1982) and zooplankton (Jeffries et al. 1984, Rolke \& Lenz 1984). The first application of image analysis to marine bacteria was the measurement of the relative size of cells in the picoplankton using an Artek 940/982 image-analysis system (Sieracki at al. 1985). Although this imageanalysis system was a significant advance in the estimation of marine microorganisms, limitations in both hardware and software prevented its use for the accu- 
rate estimation of biovolume and biomass. For example, the smallest marine bacterium was covered by only a single television picture element (pixel), making an estimation of its size impossible; even the average marine bacterium was covered by only a few pixels, making its volume estimation inaccurate at best.

We decided to develop a new image-analysis system that utilized our existing 810 image-analysis computer, but refined or replaced our remaining equipment. We have replaced the Apple Il host computer with a Macintosh computer having a $10 \mathrm{Mb}$ hard-disk. Improvements have also been made to the imaging system, including the use of a high-performance Super Chalnicon camera tube, and additional magnification lenses for the Olympus epifluorescence microscope. By writing our own software for the Macintosh to control the Artek 810 image-analysis computer, we have a user-friendly system with a flexible data collection and storage system. The new system is 3 to 5 times faster than similar systems using the Apple II and IBM PC as host computers (MacIntyre et al. unpubl.). Recently, a new image analyser has been developed by Bjornsen (1986) that includes several important hardware and software improvements useful for the analysis of bacterioplankton.

\section{METHODS}

The MacImage system is composed of an Artek 810 image-analysis computer (Artek Systems Corp., Farmingdale, New York), an Artek high-performance camera with a Super Chalnicon camera tube, an Olympus BHT-F epifluorescence microscope equipped with an Olympus 1-1.5× magnification changer, and a Macintosh 512 computer (Apple Computer, Cupertino, California) with an internal $10 \mathrm{Mb}$ Hyperdrive hard disk (General Computer, Cambridge, Massachusetts), an external disk drive and an Apple Imagewriter printer. Software for the Macintosh computer was developed using the computer language MacForth (Creative Solutions, Rockville, Maryland). For larger objects, a Wild dissecting microscope replaced the Olympus epifluorescence microscope. The detection of images by the Artek 810 is described in Sieracki et al (1985). Images from the microscope are transferred from the camera to the Artek 810 computer, where basic size measurements are made. These measurements are then transferred to the Macintosh for further analysis. A field of 350 microscopic objects can be analysed, and data transferred to the Macintosh in less than a minute.

'Fluoresbrite' carboxylate microspheres (Polysciences, Warrington, Pennsylvania) were obtained in 4 sizes: $0.21,0.57,0.88$ and $1.73 \mu \mathrm{m}$ diameter (all sizes have a standard deviation of $3 \%$ of diameter). These spheres emit a yellow-green color when examined with the epifluorescence microscope (excitation max. $458 \mathrm{~nm}$, emission max. $468 \mathrm{~nm}$ ). Spheres were diluted in distilled water to a concentration of $10^{3} \mathrm{ml}^{-1}$, filtered onto Irgalan Black stained $0.2 \mu \mathrm{m}$ Nuclepore filters, and examined using MacImage and the epifluorescence microscope, with a $100 \times$ Olympus oilimmersion objective lens.

Synechococcus clone \#223 was isolated from George's Bank in 1978 and has been maintained at the University of Rhode Island, Graduate School of Oceanography according to procedures described in Johnson \& Sieburth (1979). A 2 wk old culture of Synechococcus was fixed with $3 \%$ glutaraldehyde, filtered onto Irgalan Black stained $0.2 \mu \mathrm{m}$ Nuclepore filters, and examined using MacImage and the epifluorescence microscope under blue light, with an Olympus $100 \times$ oil-immersion objective lens.

For examination of a natural picoplankton population, a 11 sample was collected from the dock at the Narragansett Bay Campus of the University of Rhode Island and fixed with $3 \%$ glutaraldehyde. The entire sample was immediately filtered through a $6 \mu \mathrm{m}$ filter to remove larger organisms, and a $2 \mathrm{ml}$ subsample of the filtrate was placed in a sterile test tube and stained with DAPI $\left(5 \mu \mathrm{m} \mathrm{ml}^{-1}\right)$ for $5 \mathrm{~min}$ (Porter \& Feig 1980, Sieracki et al. 1985). Stained samples were filtered onto $0.2 \mu \mathrm{m}$ Nuclepore filters as described above. Slides were then examined using MacImage and the epifluorescence microcope under ultraviolet light.

Specimens of the fish larva Pseudopleuronectes americanus were collected from Narragansett Bay, Rhode Island (USA) with a $202 \mu \mathrm{m}$ Bongo net, during the months of March and April, 1986. Larvae were immediately anaesthetized with Tricaine methanesulfonate (MS222), and then fixed in $95 \%$ ethanol. Individual larvae were placed on depression slides, immersed in $95 \%$ ethanol and covered with a coverslip. Only larvae that were relatively straight were mounted. Larval measurements were made by eye using a Wild dissecting microscope at $120 \times$. Larval measurements were made by MacImage with a Wild dissecting microscope and a movable eyepiece micrometer, fitted with a phototube attached to the MacImage camera. Larvae were divided into 3 stages based on morphological characteristics. Stage 1 larvae possessed a yolk sac, onset of Stage 2 was defined by the absorption of the yolk sac, Stage 3 larvae were defined by the appearance of fin rays. A total of 108 larvae were measured (61 Stage 1, 19 Stage 2 and 28 Stage 3) for standard length (distance from snout tip to notochord tip), tail length, horizontal eye diameter, maximum trunk width and body width (excluding fin folds) immediately behind the anus. Additional mea- 
surements made with MacImage were body area, defined as the total digitized area of the larva, excluding fin folds. Additional measurements made with MacImage were the total area of the body and the area of the body in front of the tail. Measurements by eye and MacImage were made sequentially without remounting or moving the larvae, as handling has been shown to affect body measurements (Theilacker 1980).

\section{RESULTS AND DISCUSSION}

\section{Hardware and software}

The MacImage system was developed by modifying an existing Artek 810 image-analysis system. The old system consisted of an Artek 982 counter-digitizer, an Artek 940 silhouette memory unit for storage, editing, and analysis of captured images, a video monitor for the 940, a high-performance camera fitted with a Chalnicon imaging tube, and an Apple II computer with a monitor and printer. Data generated by the counter and silhouette memory unit were modified and stored by the Apple II computer. Although this system was the first to detect and count marine-sized bacteria, and the first to analyse their basic size distributions (Sieracki et al. 1985), we found it to be inadequate for measuring cell volume for 5 reasons. The first was inadequate object magnification; bacterial images were covered by too few pixels on the image screen to allow an accurate size estimation. Second, there was no operator control over the calculation of data parameters. For example, 'Length', 'Width' and 'Volume' were calculated by the Apple II program, but the algorithms for these calculations could not be modified. Although they were adequate for some images, they were often obviously inaccurate for large portions of the entire range of shapes and sizes in biological samples. Third, data produced by this system could not be manipulated or modified once they were obtained. Data files could only be read by the Apple II image-analysis program, and data editing, manipulation or graphing beyond the basic routines contained within the image-analysis program could only be made if the entire data file was entered manually into another computer program. Fourth, the graphic output from the Apple II system was of low quality. Fifth, although the Apple II system was much faster than performing the same analysis by hand, several steps in the image-analysis process seemed unnecessarily slow.

With the assistance of Artek Systems Corporation, we developed the Maclmage system by replacing several components of the old system. We first made changes to the imaging system. For measuring small objects such as bacteria, the magnification of the image is important for accurate sizing. Newell (1984) and Caldwell \& Germida (1985) have demonstrated that the addition of magnification lens to the light microscope, which increases magnification above the theoretical limit of resolution, can significantly increase the pixel coverage of bacterial images without degrading their images. The addition of an Olympus magnification changer, with a $1.50 \times$ lens, increased the magnification on the Artek image monitor screen from $1200 \times\left(0.26 \mu \mathrm{m} \mathrm{pixel}^{-1}\right)$ to $2000 \times$ $\left(0.15 \mu \mathrm{m}\right.$ pixel $\left.^{-1}\right)$. This additional magnification, however, reduces the light reaching the camera, making the detection of small objects such as bacteria difficult. In order to make the camera more sensitive to the resulting low light levels, we replaced our Chalnicon imaging tube with a more sensitive Super Chalnicon tube.

In order to reduce the cumbersomeness of the original Artek image-analysis system (Sieracki et al. 1985, Fig. 3), Artek Systems Corporation repackaged the 940/982 image-analysis units of the Artek 810, along with its monitor, into a single case, resulting in a more compact system. Rather than attempting to modify the existing Apple II software, we decided that the time would be better spent by interfacing the repackaged Artek 810 system to a more powerful and flexible computer. The Apple Macintosh with a Hyperdrive internal $10 \mathrm{MB}$ hard-disk was the logical choice for this new host computer, due to its 68000 microprocessor, high-resolution screen, ease of use, compact size, portability, and large software base. Programs for the Macintosh were developed $a b$ initio, not as a modification of the Apple II software. A version of Forth from Creative Solutions was chosen as the language for software development. Forth is a powerful, fast computer language that allows extensive control over computer hardware, and is used for a number of scientific applications (Maclntyre 1985). The present configuration of Maclmage is shown in Fig. 1.

The software developed for the Macintosh communicates with the Artek 810 image-analysis computer through the serial port on the Macintosh using a terminal-communication program written in Forth. Control over the function of the 810 is achieved with the Macintosh by using the pulldown windows and mouse commands typical of a Macintosh application. The basic functions of analysing single or multiple objects, deleting unwanted objects, or isolating a single object on the Artek screen are accomplished using 'push buttons' on the Macintosh screen (Fig. 2). These functions are selected by moving the cursor over these push buttons, and pressing the mouse button.

Images detected by the camera are displayed on the Artek screen as an analog image. Setting a variable grey-level threshold level places a binary silhouette 


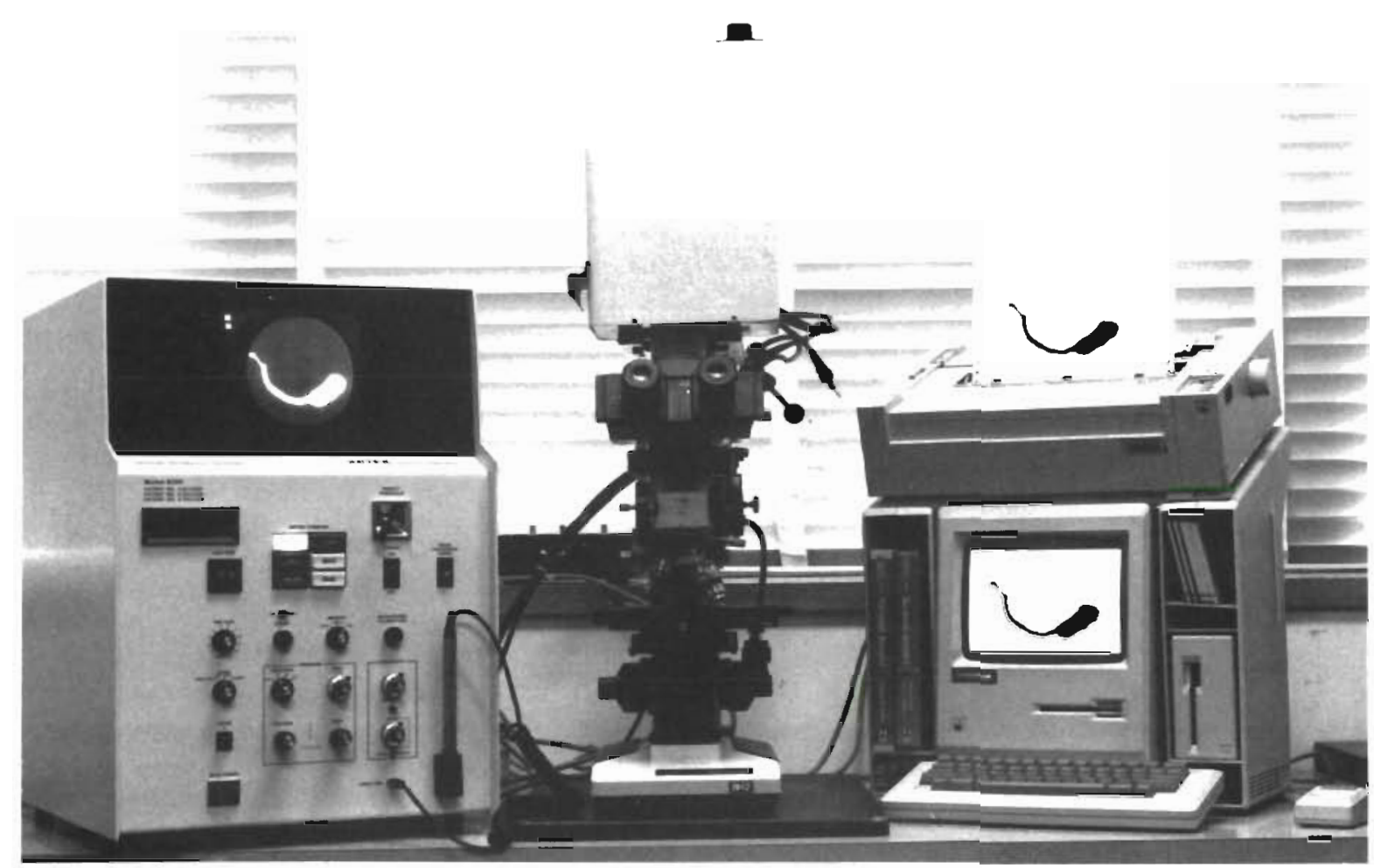

Fig. 1. Photograph of MacImage system showing epifluorescence microscope with Super Chalnicon video camera (center), Artek image analysis system (left) and Macintosh with printer (right)

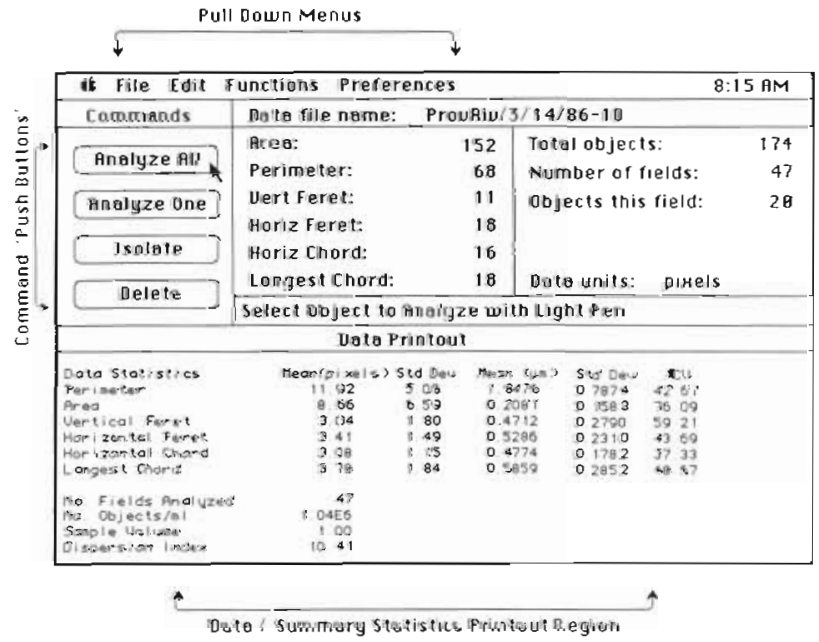

Fig. 2. Appearance of Macintosh screen when using MacImage program. Command push buttons on the upper left of the screen control main Maclmage functions. Data statistics are printed on the bottom of the screen

over the analog image. When an analysis or imageediting command is selected, the silhouette image is frozen on the Artek screen and stored in the $810 \mathrm{com}$ puter memory. This ability to freeze silhouette images on the screen is particularly important for autofluorescent or fluorochrome-stained bacterial samples, which quickly fade when exposed to UV or blue light. When the Macintosh program requests that an analysis be made on one or several images on the Artek screen, the 810 computer analyses these objects and transfers data to the Macintosh. The 6 basic measurements that are made and transferred for each object are: Area Perimeter, Vertical Feret, Horizontal Feret, Horizontal Chord, and Longest Chord. The horizontal and vertical ferets are the dimensions of a tangent rectangle surrounding the image (Feret 1931). The horizontal chord is the longest horizontal line contained within the image. The longest chord is the longest of the vertical feret, horizontal feret, and 2 ferets at $45^{\circ}$ and $135^{\circ}$ through the center of the rectangle. The area is the total count of pixels covering the object, and the perimeter is the distance between the endpoints of the horizontal lines that make up the object.

Data files, once created, can be edited from within the MacImage program, and can be added to at a later time. At any time during or after data analysis, data can be graphed as a size-distribution histogram, and summary statistics, or the entire data file, can be printed. The program also includes a calibration routine that allows calculation of the width of a pixel in nanometers, micrometers or millimeters, a value which is used by the program to convert pixel data to scaled numbers. An example of graphic output from the program is presented in Fig. 3. 


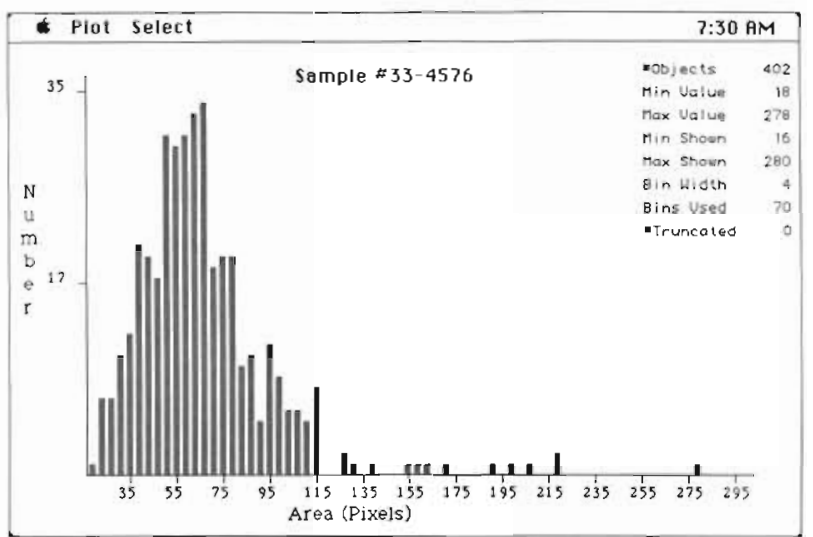

Fig. 3. Appearance of Macintosh screen when an area histogram is requested. Data are automatically sorted into bins and summary plot statistics are printed in the upper right of the screen

In the original Artek 940/982 image-analysis system, the Apple II computer automatically calculated a number of object parameters from the basic data described above, including circularity, length, width, and biovolume. This approach can lead to misleading results due to the heterogeneity of object shapes in biological samples. For the MacImage system, we have chosen to limit the parameters that are calculated automatically to the 6 basic measurements described above. For further data analysis, such as calculation of biovolume or biomass, the basic measurements may be transferred to the spreadsheet 'Microsoft Excel', a versatile numerical analysis and plotting program. This forces the user to consider equations appropriate to the objects being measured. Maclmage saves data files in a format that can be read directly by the Excel program. The same ASCII file format used by Excel could be used to transfer data to word processing programs, or to our main-frame computer.

In addition to these functions, the MacImage system also allows images themselves to be stored. Any silhouette image captured on the Artek screen can be transferred to the Macintosh screen. This allows images to be viewed on the monitor of the Macintosh, and to be stored on its hard-disk. In addition, stored images can be transferred back to the Artek $810 \mathrm{com}$ puter for later analysis, and manual length measurements can be made on the Macintosh screen by drawing lines with the mouse. This image-transfer function serves as both a visual documentation of analysed images, and a convenient way to store interesting or complex images that require further analysis. Stored images can also be transferred to the MacPaint program, a graphics program that allows transferred images to be enhanced, labelled and printed as publication-quality drawings (Estep \& Sieburth 1985).

\section{Digitization errors}

While a full discussion of the problems associated with digitization is beyond the scope of this paper (Inoué 1986), 4 aspects are relevant. Firstly, 'empty magnification', which enlarges the image without adding detail, is useful since it increases the number of pixels covering the images, and more nearly approximates the true shape of objects. Secondly, the jagged contour introduced by digitizing small objects means that estimates of 'perimeter' are not likely to be useful parameters until they are smoothed, as by a spline function, or the 'convex perimeter' used by Bjornsen (1986). Thirdly, the indeterminate position of small circles with respect to the pixel grid, and the variable orientation of non-circular objects, increase the variance of all estimates. Fourthly, the grey-level threshold chosen to delineate the contour must be chosen by calibration against known objects.

Additional magnification, and its effect on these considerations, are shown in Fig. 4 which illustrates a

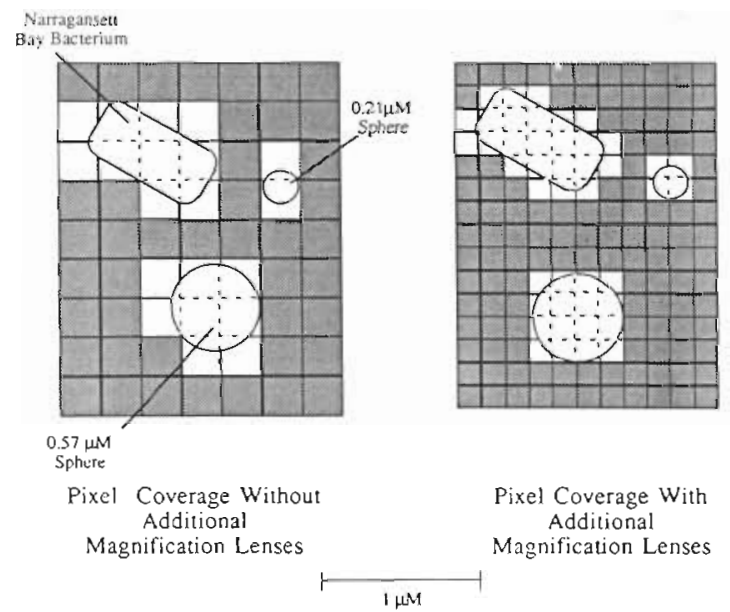

Fig. 4. Effect of increased magnification on the accuracy of measuring small objects. Left side of figure: 3 microscopic objects on a grid of grey pixels with an object size:pixel size ratio when the system is configured without additional magnification lenses. Addition of magnification lenses increases object size:pixel size ratio as shown on right side of the figure, giving a more accurate estimation of object size and shape. The light grey pixels on the periphery of the objects may or may not be lit, depending on grey-level threshold value

$0.21 \mu \mathrm{m}$ and a $0.57 \mu \mathrm{m}$ sphere, and a Narragansett Bay bacterium on a grid of pixels whose size relative to the objects is determined by the presence or absence of additional magnification lenses. The light grey pixels on the periphery of the objects may or may not be lit, depending on the grey-level threshold value. The pixel grid on the left represents the pixel to object size ratio as the system was configured by Sieracki et al. 
(1985). Additional magnification in the present system, as shown in the right side of the figure, results in a lower object size to pixel size ratio, and object contours that more accurately reflect the true object shape.

\section{Fluorescent microspheres}

Some 300 fluorescent spheres of each size were analysed with Maclmage, and data parameters were transferred to Excel for calculation of diameter, volume and shape estimations. Fluorescent sphere diameters were calculated using the formula in Equation 1.

$$
\mathrm{D}=(\text { Vertical feret }+ \text { Horizontal feret }) / 2
$$

Volumes were calculated from both the diameter (Equation 2) and the area (Equation 3).

$$
\begin{aligned}
& \text { Volume }_{\text {Diam }}=\pi D^{3 / 6} \\
& \text { Volume }_{\text {Area }}=\left(4 A^{3 / 2}\right) /\left(3 \pi^{1 / 2}\right)
\end{aligned}
$$

The results of the microsphere sizings are presented in Table 1. For the spheres with diameters of $1.73,0.88$ and $0.57 \mu \mathrm{m}$, the MacImage system estimated diameters, areas and volumes within $6 \%$ of the mean values as stated by the manufacturer. In addition, standard deviations were similar for the manufacturer's specifications and the MacImage system. Spheres of $0.21 \mu \mathrm{m}$ diameter, near the limit of resolution of the light microscope, were overestimated in diameter by $24 \%$, in area by $80 \%$ and in volume by $118 \%$. Particles of $0.21 \mu \mathrm{m}$ size are usually a minor part of picoplankton populations. Although virus particles in the femtoplankton can be detected by eye, and perhaps by image analysis, they cannot be detected using MacImage with the additional magnification lenses.

In order to examine the nature of the image shape detected by the image-analysis system, and the effect of digitization error thereon, we calculated Feret area (Equation 4) and $\Delta$ Feret (Equation 5).

Feret area $=$ Horizontal feret $\times$ Vertical feret

Table 1. Accuracy of the Maclmage system on bacterial and protist-sized objects. Comparison of manufacturer's stated sizes of 4 fluorescent microspheres compared to their sizes as determined using MacImage

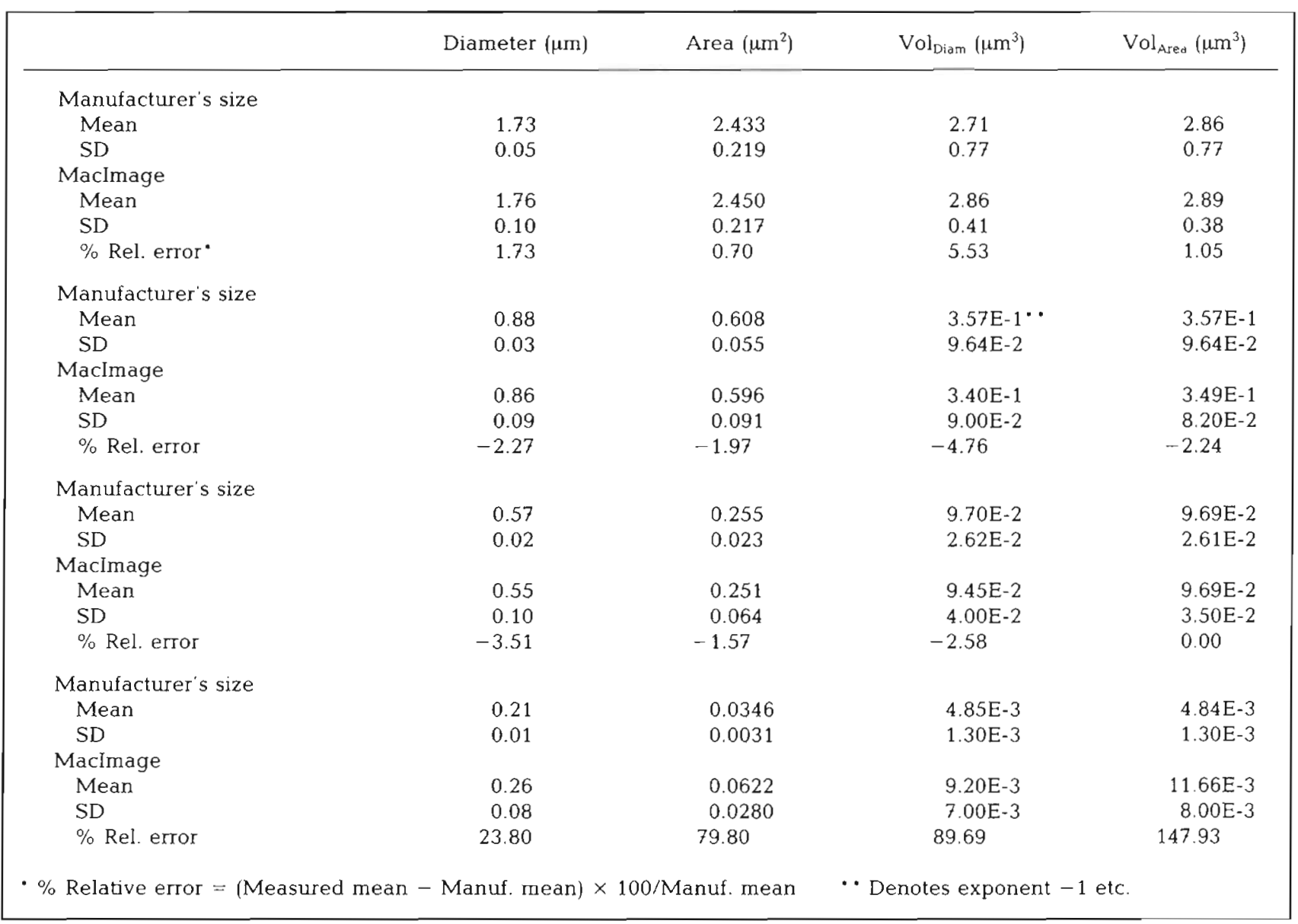


$\Delta$ Feret $=$ Horizontal feret - Vertical feret

For perfect spheres, $\Delta$ Feret should be zero and the ratio of Feret area to Object area should be $4 / \pi=1.273$, as indicated by the vertical line on each graph in

A Effect of Ferel Area/Object Area
and Feret on Shape Determination of
$0.57 \mu \mathrm{m}$ Fluorescent Spheres

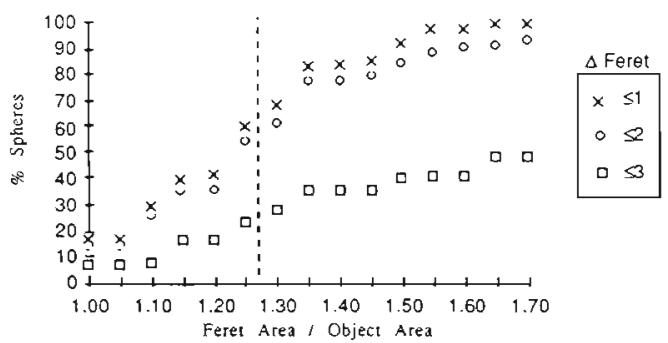

$\mathrm{B}$

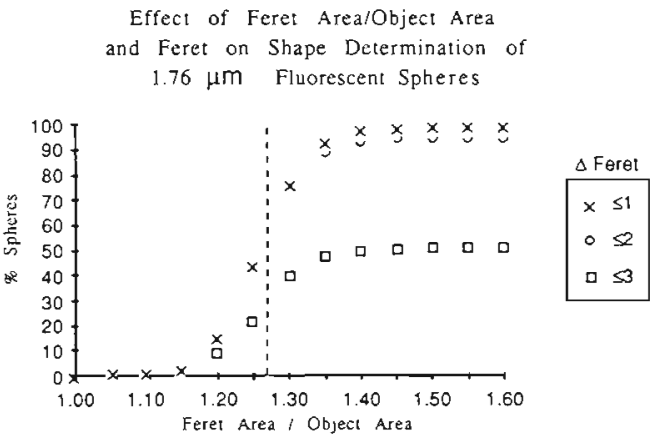

Fig. 5. Plots of Feret area/Object area and $\Delta$ Feret for the $0.57 \mu \mathrm{m}$ and $1.76 \mu \mathrm{m}$ spheres

Fig. 5. The $\Delta$ Feret lines cross this theoretical value at about the ' $50 \%$ spheres' value, as they should. Plots of Feret area/Object area (FA/OA) for $\Delta$ Feret's $\leq 1, \leq 2$, and $\leq 3$ are presented, since for both the 1.73 and $0.57 \mu \mathrm{m}$ spheres, approximately $50 \%$ of the spheres have a $\Delta$ Feret greater than 1 , as expected for circles not centered on the pixel grid. The maximum $\Delta$ Feret observed, 3, arises from a small asymmetry of the Chalnicon raster scan, which makes circles longer than they are tall. In terms of both the $\Delta$ Feret and the FA/ $O A$ ratio, digitization error results in underestimation of the number of objects that are spheres.

Proper adjustment of the fluorescent light system is essential for the accurate estimation of fluorescent objects. When viewed under maximum fluorescent light intensity, fluorescent objects exhibit a halo of flaring light surrounding their images. To avoid the overestimation of the size of these images, it is important to reduce the fluorescent light source to a level that removes this flaring, while still allowing sufficiently bright images for detection by the imageanalysis system. All of the spheres measured above were viewed under reduced fluorescent light, adjusted with the fluorescent tube diaphragm and a diaphragm within the objective lens. Analysis of the same spheres without these adjustments resulted in sizes up to 2 times larger than their actual values.

\section{Synechococcus}

Synechococcus clone \#223 exhibits typical singlecelled cyanobacterial morphology, with relatively constant cell width. An image transfer prepared with Maclmage, and enhanced with text using the MacPaint program, is presented in Fig. $6 \mathrm{~A}$. In addition to the single, rod-shaped cells, dividing and elongated cells are also visible.

\section{A}

Synechococcus, Image Transfer From MacImage

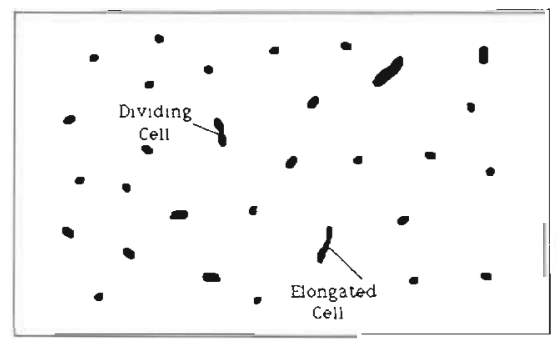

$\mathrm{B}$

Synechococcus \#223 - Cell Length \& Width

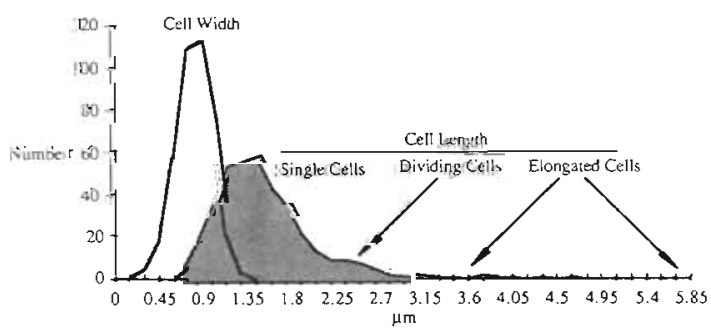

Fig. 6. Results of image analysis on Synechococcus \#223. (A) Image transfer to Macintosh of a typical microscopic field. (B) Summary cell length and width plot; note uniform cell width and variable cell length

A total of 400 Synechococcus cells were analysed with MacImage, and image transfers were prepared of representative fields. As with the fluorescent spheres, data from MacImage were transferred to Excel for calculation of volume. For Synechococcus we chose to calculate volumes assuming that the cells were cylinders. Cell length was estimated by examination of the FA/OA ratio, under the assumption that a vertically or horizontally oriented cylinder will have a Feret area nearly equal to the Object area, while a cylinder 
oriented at $45^{\circ}$ will have a much larger FA/OA ratio Again, digitization error must be considered in these estimations, and equal Feret areas and Object areas should not be expected. We chose to divide the cells into 3 categories, those with nearly equal Feret area and Object areas, those with very different Feret area and Object areas, and those with intermediate values These cells were then assumed to be lying at $0^{\circ}$ or $90^{\circ}$, $45^{\circ}$, and $22.5^{\circ}$ or $67.5^{\circ}$, respectively. Division into these categories was determined by examination of the FA/ $O A$ ratio for the entire data set, and different $F A / O A$ ratios were entered into Excel until approximately equal sorting into the 3 categories resulted. Final results were:

If $\mathrm{FA} / \mathrm{OA}$ ratio $<1.4$ then

Length $=$ Max (Vertical feret, Horizontal feret)

If $\mathrm{FA} / \mathrm{OA}$ ratio $>1.8$ then

Length $=\left\{(\text { Vertical feret })^{2}+(\text { Horizontal feret })^{2}\right\}^{1 / 2}$

If $1.8>\mathrm{FA} / \mathrm{OA}>1.4$ then

Length $=$ Mean of lengths Equation 6 \& Equation 7

This demonstrates the importance of data transfer to Excel, as it allows one to ask 'what if' questions about the data that one has collected.

Synechococcus cell volumes were then calculated from both areas and lengths:

$$
\begin{aligned}
& \text { Volume }_{\text {Dram }}=\pi D^{2} \mathrm{~L} / 4 \\
& \text { Volume }_{\text {Area }}=\pi \mathrm{A}^{2} / 4 \mathrm{~L}
\end{aligned}
$$

Mean length was $1.70 \pm 0.69 \mu \mathrm{m}$, mean width was $0.91 \pm 0.31 \mu \mathrm{m}$ and mean volume from area was $1.20 \pm$ $0.70 \mathrm{\mu m}^{3}$. A size-distribution histogram of cell length and width is presented in Fig. 6B. Cell widths occupy a narrow band centered around $0.9 \mu \mathrm{m}$, while cell lengths have a large peak at about $1.4 \mu \mathrm{m}$, representing single cells, a second, smaller peak at about $2.5 \mu \mathrm{m}$, representing dividing cells, and scattered peaks at longer lengths, representing elongated cells.

\section{Narragansett Bay picoplankton}

Narragansett Bay picoplankton populations were analysed for size, shape and abundance. A total of 500 picoplankton cells were analysed using MacImage. Unlike the fluorescent spheres and cylindrical Synechococcus cells described above, Narragansett Bay picoplankton populations consist of a number of simple shapes and sizes. Data from the picoplankton cells analysed in this sample were transferred to Excel for division into shape categories. We decided to divide the cells into 3 shapes: spheres, prolate spheroids and cylinders. Data from the $0.21 \mu \mathrm{m}$ spheres suggest that an accurate size and shape estimation cannot be made on cells covered by 4 pixels or less. We decided therefore, to treat all objects of 4 or fewer pixels (Area $\leq 0.09 \mu \mathrm{m}^{2}$ ) as spheres, or 'MiniBacteria'. Cells larger than 4 pixels were sorted based on a combination of $\mathrm{FA} / \mathrm{OA}$ ratio and $\triangle$ Feret using the criteria listed in Table 2.

Table 2. Criteria for sorting Narragansett Bay picoplankton into shape categories

\begin{tabular}{|lllll|}
\hline \multicolumn{5}{c|}{ FA/OA } \\
$\Delta$ Feret & $=1$ & $\leq 1.15$ & $\leq 1.35$, & $>1.35$ \\
& & & $>1.15$ & \\
\hline$\leq 2$ & Cylinder & Cylinder & Sphere & Pro.sph. \\
$\leq 4,>2$ & Cylinder & Cylinder & Pro. sph. & Pro.sph. \\
$>4$ & Cylinder & Cylinder & Cylinder & Cylinder \\
\hline
\end{tabular}

Narragansett Bay bacterial volumes were calculated using the length/width estimations from feret values. Results of their sorting into categories, and resulting biovolume distributions are presented in Fig. 7. Cells Biovolume Distribution of the Four Size Classes
of Narragansett Bay Picoplankton

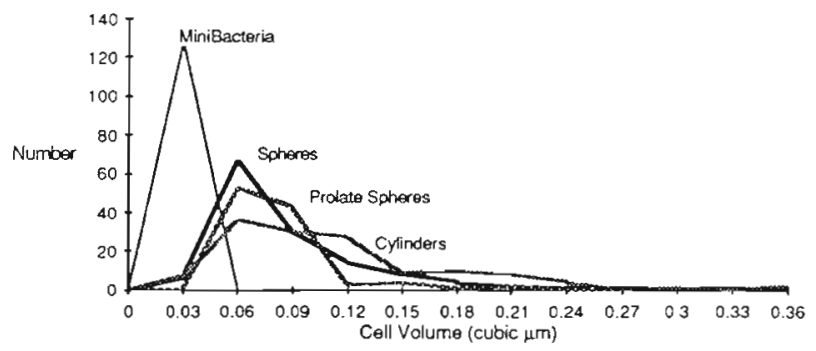

Fig. 7. Cell volume plot for a natural sample of Narragansett Bay picoplankton. Cell volumes calculated in Excel using 4 shape catagories

are about equally divided among spheres, prolate spheroids, cylinders and 'MiniBacteria'. Formulae for calculation of width, and volume are summarized in Fig. 8.

Total count calculated by MacImage was $1.04 \times 10^{6}$ $\mathrm{ml}^{-1}$. This value is in agreement with previous bacterial abundance estimations in Narragansett Bay (Davis et al. 1985, Sieracki et al. 1985). Bacterial biovolume was $0.066 \mu \mathrm{m}^{3} \pm 0.0068$. Use of the most recent volume

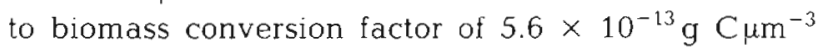
(Bratbak 1985) results in a biomass estimation for the sample of $3.69 \times 10^{-14} \mathrm{~g} \mathrm{C}$ (mean bacterium) ${ }^{-1}$. Biomass for the entire bacterial population was $38.3 \mu \mathrm{g}$ $\mathrm{Cl}^{-1}$.

Physical chemists have long realized that chemical reactions preferentially occur at surfaces. Accordingly, the surface area of bacteria is an important parameter 


\begin{tabular}{|c|c|c|c|c|c|}
\hline $\begin{array}{l}\text { Object } \\
\text { Slupe }\end{array}$ & 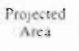 & $\begin{array}{l}\text { Volume } \\
\text { (fram D) }\end{array}$ & $\frac{D}{\text { (Fsom Acea) }}$ & $\begin{array}{l}\text { Volume } \\
\text { (Frog Ares) }\end{array}$ & Bacourface Atea \\
\hline$\underbrace{\text { Cylinder }}_{0}$ & DL & $\frac{\pi D^{2} L}{4}$ & $\frac{A}{L}$ & $\frac{\pi A^{3}}{4 L}$ & $\pi D\{L+(D / 2)\}$ \\
\hline $\begin{array}{l}\text { Prolate } \\
\text { Spheriod }\end{array}$ & $\pi \mathrm{DL}$ & $\pi D^{2} L$ & $4 \mathrm{~A}$ & $8 \mathrm{~A}^{2}$ & 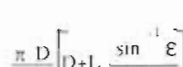 \\
\hline$\underbrace{}_{0}$ & 4 & 6 & $\pi \mathrm{L}$ & $3 \pi \mathrm{L}$ & $\overline{2}[\mathrm{D}+\mathrm{L} \bar{\varepsilon}$ \\
\hline$\overbrace{0}^{\text {Spherc }}$ & $\frac{\pi D^{2}}{4}$ & $\frac{\pi D^{3}}{6}$ & {$\left[\frac{4 \mathrm{~A}}{\pi}\right]^{1 / 2}$} & $\frac{4 A^{37}}{3 \pi^{12}}$ & $\pi D^{2}$ \\
\hline
\end{tabular}

Fig. 8. Summary of volume and width formulae used for a Narragansett Bay picoplankton population

for estimates of diffusion, nutrient turnover, residence times, and chemotaxis. Calculations of protistan and bacterial surface areas were made by Williams (1984), based on the assumption that cells could be divided into uniform size classes, but biologists have so far made little use of this parameter, perhaps because of the difficulty involved in its calculation.

The last column of Fig. 8 shows the formulae we use to calculate biosurface area, where $\varepsilon$, the elliptical eccentricity, is defined as:

$$
\varepsilon=\left[1-(\mathrm{D} / \mathrm{L})^{2}\right]^{1 / 2}
$$

This equation results in a biosurface area of $8.14 \times$ $10^{5}{\mu \mathrm{m}^{2}} \mathrm{ml}^{-1}$ for Narragansett Bay picoplankton, or roughly $1 \mu^{2} \mathrm{~m}^{2}$ acterium ${ }^{-1}$.

\section{Pseudopleuronectes americanus}

Fish larval parameters measured by eye and with MacImage are summarized in Fig. 9. Because fish larvae are more complex in shape than the other objects analysed in this study, it is necessary to orient them on the image screen before they are analysed. This makes their measurement no faster than measurement by eye, however, a larger number of size parameters are measured by Maclmage, and some of these, such as perimeter and area, could be measured by eye only with great difficulty (if at all).

Mean and standard deviation on the 5 parameters measured by eye and MacImage are summarized in Table 3 . The correlation between standard length measured by eye and Maclmage is summarized in Fig. 10A. Standard length can be measured on larvae that are relatively straight. Unfortunately, many larvae are significantly bent by the fixation process. A plot of standard length vs square root of body area by MacImage suggests that body area may also be used in calculations of growth rate (Fig. 10B). The use of body
Winter Flounder Larva / Yolk Sac Stage

Parameters Measured by Eye

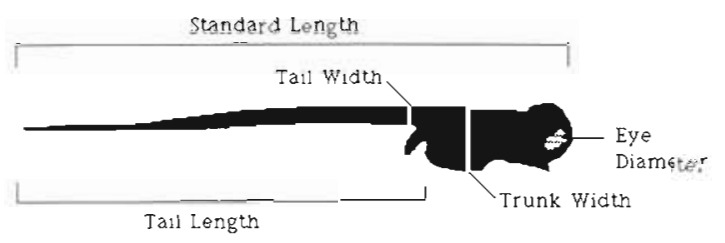

Parameters Measured by Mac Image

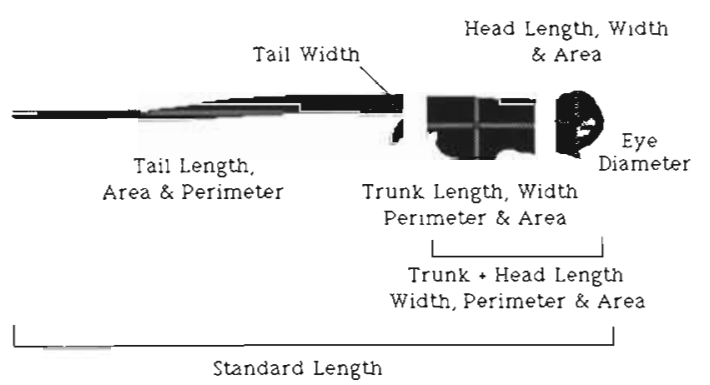

Fig. 9. Measurements made on Pseudopleuronectes americanus by eye and Maclmage

A

$$
\text { Eye vs Maclmage - Standard Length }
$$

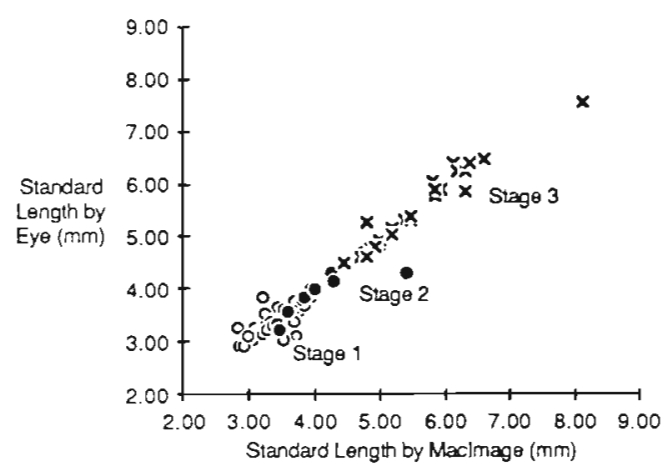

B Sqrt Body Area vs Standard Length

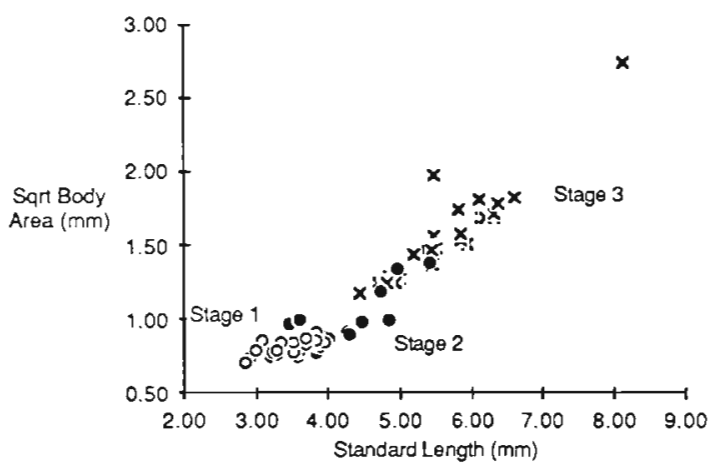

Fig. 10. (A) Plot of standard length of Pseudopleuronectes americanus measured by eye vs standard length as measured by Maclmage. (B) Correlation of standard length and square root body area of Pseudopleuronectes americanus as measured by Maclmage 
Table 3. Comparison of mean winter flounder size measurements as measured by MacImage and by using the eyepiece micrometer (units for all measurements $=\mathrm{mm}$ )

\begin{tabular}{|c|c|c|c|c|c|}
\hline & Standard length & Trunk width & Tail length & Tail width & Eye diameter \\
\hline \multicolumn{6}{|c|}{ Yolk sac stage $(n=61)$} \\
\hline Mean & 3.46 & 0.48 & 2.44 & 0.13 & 0.20 \\
\hline SD & 0.25 & 0.04 & 0.21 & 0.01 & 0.02 \\
\hline \multicolumn{6}{|c|}{ By Maclmage: } \\
\hline Mean & 3.48 & 0.46 & 2.36 & 0.15 & 0.23 \\
\hline $\mathrm{SD}$ & 0.27 & 0.06 & 0.25 & 0.04 & 0.01 \\
\hline \multicolumn{6}{|c|}{ 2nd stage $(n=19)$} \\
\hline Mean & 3.98 & 0.38 & 2.80 & 0.28 & 0.24 \\
\hline $\mathrm{SD}$ & 0.48 & 0.07 & 0.36 & 0.03 & 0.06 \\
\hline \multicolumn{6}{|c|}{ By MacImage: } \\
\hline Mean & 4.08 & 0.47 & 2.82 & 0.22 & 0.23 \\
\hline $\mathrm{SD}$ & 0.58 & 0.09 & 0.36 & 0.17 & 0.04 \\
\hline \multicolumn{6}{|c|}{ 3rd stage $(n=28)$} \\
\hline Mean & 5.58 & 0.80 & 3.65 & 0.34 & 0.30 \\
\hline $\mathrm{SD}$ & 0.71 & 0.20 & 0.43 & 0.16 & 0.08 \\
\hline \multicolumn{6}{|c|}{ By MacImage: } \\
\hline Mean & 5.63 & 0.81 & 3.68 & 0.37 & 0.25 \\
\hline $\mathrm{SD}$ & 0.76 & 0.20 & 0.33 & 0.17 & 0.06 \\
\hline
\end{tabular}

area instead of length, might circumvent the problem of having to straighten bent larvae.

\section{SUMMARY}

Our results indicate that MacImage can be used for accurate estimation of abundance, size and volume of a wide range of marine organisms. With the present system, images down to about $0.5 \mu \mathrm{m}$ effective diameter can be analysed precisely. This lower size limit is the result of both the limit of resolution of the light microscope, and also the relation between pixel size and object size. In order to obtain accurate sizing, objects must be covered by several pixels. By decreasing pixel width from 0.259 to $0.155 \mu \mathrm{m}$, we are able to cover all but the $0.21 \mu \mathrm{m}$ spheres and the smallest of Narragansett Bay bacteria with enough pixels to give an accurate size estimation. Further magnification of images requires arithmetic-image addition, as in the image-analysis system recently described by Bjørnsen (1986).

Successful image analysis is the result of many factors including the forming of a sharp image, correctly orienting the image in the field, proper detection of the image by the image-analysis system, and analysis of the data in a way appropriate to the nature of the images measured. Careful attention must be paid to the difference between the mathematicians' smooth curves and the jagged approximations of digitization. In order to meet the changing needs of the user of the image-analysis system, flexibility of data transfer between programs is essential. Data collected by the MacImage program for this study was later manipulated by MacDraft, MacDraw, MacPaint and Microsoft Excel, all without re-entering any of the data.

Despite its usefulness, the Artek MacImage system does have some serious limitations. Although we do not have access to the software within the Artek 810 computer, we have determined that the algorithms responsible for the estimation of longest chord and perimeter are not accurate, possibly due to an error in an integer square root function. We therefore do not use these parameters in our analysis routines. Artek Systems Corp. is currently working to correct these problems.

Acknowledgements. This work is a portion of Estep's Ph.D thesis; MacIntyre contributed consultations on Forth, and numerical treatment of the data; Hjörleifsson provided the fish larvae and made visual measurements on them; all in the laboratory of and under the supervision of Sieburth. We thank Paul Johnson for assistance with this work. We also thank Mike Bender of Artek Systems Corp. We further acknowledge M. Sieracki for critical reading of the manuscript. The development of this image-analysis system was supported by the National Science Foundation by Grants OCE-8121881 and OCE-8511365 (to J.McN. Sieburth), and by an equipment grant from Artek Systems Corp. 


\section{LITERATURE CITED}

Bjornsen, P. K. (1986). Automatic determination of bacterioplankton biomass by means of image analysis. Appl. environ. Microbiol. 51: 1199-1204

Blaxter, J. H. S., Hempel, G. (1963). The influence of egg size on herring larvae. J. Cons. perm. int. Explor Mer 28: $211-216$

Bratbak, G. (1985). Bacterial biovolume and biomass estimations. Appl. environ. Microbiol. 49: 1488-1493

Bulow, F. J. (1970). RNA-DNAratios as indicators of recent growth rates of a fish. J. Fish. Res. Bd Can. 27: 2243-2349

Caldwell, D. E., Germida, J. J. (1985). Evaluation of difference imagery for visualizing and quantitating microbial growth. Can. J. Microbiol. 31: 35-44

Davis, P. G., Caron, D. A., Johnson, P. W., Sieburth, J. McN. (1985). Phototrophic and apochlorotic components of picoplankton and nanoplankton in the North Atlantic: geographic, vertical, seasonal and diel distributions. Mar. Ecol. Prog. Ser. 21: 15-26

Estep, K. W., Sieburth, J. McN. (1985). Interactive manuscript preparation and graphics. Bioscience 35 : 367-371

Feret, L. R. (1931). Particle size of pulverulent materials. New Intern. Assoc. Testing Materials

Fuhrman, J. A. (1981). Influence of method on the apparent. size distribution of bacterioplankton cells: epifluorescence microscopy compared to scanning electron microscopy. Mar. Ecol. Prog. Ser. 5: 103-106

Furuya, K. (1982). Measurement of phytoplankton standing stock using an image analyser system. Bull. Plank. Soc. Jap. 29: 133-135

Ingram, M., Preston, K., Jr. (1970). Automatic image analysis of blood cells. Scient. Am. 223: 72--82

Inové, S. (1986). Video microscopy. Plenum, New York

Jeffries, H. P., Berman, M. S., Poularikas, A. D., Katsinis, C., Melas, I., Sherman, K., Bivins, L. (1984). Automated sizing, counting and identification of zooplankton by pattern recognition. Mar. Biol. 78: 329-334

Johnson, P. W., Sieburth, J. McN. (1979). Chroococcoid cyanobacteria in the sea: a ubiquitous and diverse phototrophic biomass. Limnol. Oceanogr. 24: 928-935
Laanbroek, H. J., Verplanke, J. C. (1986). Tidal variations in bacterial biomass, productivity and oxygen uptake rates in a shallow channel in the Oosterschelde basin. The Netherlands. Mar Ecol. Prog. Ser. 29: 1-5

Lasker, R. (1981). Marine fish larvae: morphology, ecology and relation to fisheries. Univ. Wash. Press, Seattle

MacIntyre, F. (1985). Forth: the optimum language for microcomputers. Am. Lab. 17: 18-26

Newell, S. Y (1984). Modification of the gelatin-matrix method for enumeration of respiring bacterial cells for use with salt-marsh water samples. Appl. environ. Microbiol. 47: $873-875$

Pettipher, G. L., Rodrigues, U. M. (1982). Semi-automated counting of bacteria and somatic cells in milk using epifluorescence microscopy and television image analysis. J. appl. Bact. 53: 323-329

Porter, K. G., Feig, Y. S. (1980). The use of DAPI for identifying and counting aquatic microflora. Limnol. Oceanogr. 25: 943-948

Rolke, M., Lenz, J. (1984). Size structure analysis of zooplankton samples by means of an automated image analysing system. J. Plankton Res. 6: 637-645

Sieracki, M. E., Johnson, P. W., Sieburth, J. McN. (1985). Detection, enumeration, and sizing of planktonic bacteria by image-analysed epifluorescence microscopy. Appl. environ. Microbiol. 49: 799-810

Theilacker, G. H. (1980). Changes in body measurements of larval northern anchovy, Engraulis mordax, and other fishes due to handling and preservation. Fish. Bull. U.S. 78: 685-692

Watson, W. H. (1952). Automatic counting of microscopic particles. Nature, Lond. 169: 518-520

Williams, P. J. leB. (1984). Bacterial production in the marine food chain: the emperor's new suit of clothes? In: Fasham, M. J. R. (ed.) Flows of energy and material in marine ecosystems. Plenum Press, New York. p. 271-299

Zimmermann, R. (1977). Estimation of bacterial number and biomass by epifluorescence microscopy and scanning electron microscopy. In: Rheinheimer, G. (ed.) Microbial ecology of a brackish water environment. Springer-Verlag, New York, p. 103-120 